\title{
BMJ Open Mainstreaming of genomic medicine in gastroenterology, present and future: a nationwide survey of UK gastroenterology trainees
}

\author{
Ibrahim Al Bakir (D) , ${ }^{1,2}$ Gregory Malcolm Sebepos-Rogers, ${ }^{3}$ Hilary Burton, ${ }^{4}$ \\ Kevin J Monahan ${ }^{5,6}$
}

To cite: Al Bakir I, SebeposRogers GM, Burton $\mathrm{H}$, et al. Mainstreaming of genomic medicine in gastroenterology, present and future: a nationwide survey of UK gastroenterology trainees. BMJ Open 2019;9:e030505. doi:10.1136/ bmjopen-2019-030505

- Prepublication history and additional material for this paper are available online. To view these files, please visit the journal online (http://dx.doi. org/10.1136/bmjopen-2019030505).

Received 20 March 2019 Revised 24 July 2019 Accepted 07 August 2019
Check for updates

(C) Author(s) (or their employer(s)) 2019. Re-use permitted under CC BY-NC. No commercial re-use. See rights and permissions. Published by BMJ.

For numbered affiliations see end of article.

Correspondence to

Kevin J Monahan;

k.monahan@imperial.ac.uk

\section{ABSTRACT}

Objective Genomics and personalised medicine are increasingly relevant for patients with gastroenterological conditions. We aim to capture the current state of genomics training in gastroenterology to review current understanding, clinical experience and long-term educational needs of UK trainees.

Design and setting $A$ web-based nationwide survey of all UK gastroenterology specialty trainees was conducted in 2017.

Results 100 trainees (14\% of UK gastroenterology trainees) completed this survey. Only $9 \%$ and $16 \%$ of respondents believe that their local training programme adequately prepares them for the future clinical practice using genomic medicine and personalised medicine, respectively. Barriers identified include the need for greater trainee education $(95 \%)$, inadequate clinical guidance to base interventions on the results of genomic testing (53\%), concerns over misinterpretation by patients (43\%) and overuse/misuse of testing by clinicians (34\%).

Survey respondents felt prepared to perform HFE genotyping ( $(98 \%)$, assess TPMT status $(97 \%)$ and interpret HLA subtyping for suspected coeliac disease $(85 \%)$. However, only a minority felt prepared to perform the following investigations: polyposis screening (34\%), hereditary pancreatitis screening (30\%), testing for Lynch yndrome (33\%) and KRAS testing for colorectal cancer (20\%).

Most respondents would support holding dedicated training days on genomic medicine (83\%), formal training provisions for the mainstreaming of genomic testing $(64 \%)$, an update to the UK gastroenterology specialty training curriculum and examinations (57\%) and betterdefined referral pathways for local genomic services $(91 \%)$.

Conclusion Most gastroenterology trainees in this survey feel ill equipped to practise genomic and personalised medicine as consultants. We propose specific revisions to the UK gastroenterology specialty curriculum that addresses trainees needs.

\section{INTRODUCTION}

The last decade of scientific research has been marked by an explosion in next-generation sequencing studies ${ }^{1}$ conducted to advance

\section{Strengths and limitations of this study}

- This is the largest survey of National Health Service staff addressing their views and experiences of genomic mainstreaming and precision medicine, in the context of one of the larger hospital-based medical specialties.

- While respondents represent less than $15 \%$ of all UK gastroenterology trainees, the cohort is sufficiently large, with clear geographical, contextual and seniority variation among respondents to make conclusions generalisable.

- There was no information on non-respondents due to the nature of this anonymised online survey; however, the responses received would go against participation bias in the favour of trainees with existing research and/or clinical experience in genomic medicine.

our understanding of disease risk, behaviour and response to medical therapy in a variety of gastrointestinal conditions, ${ }^{2}$ including but not limited to pharmacogenomics and drug-induced liver injury, inflammatory bowel disease (IBD), hereditary hepatic and pancreatobiliary disease, hereditary and acquired premalignant diseases (from Barrett's oesophagus to polyposis syndromes), and virtually all types of gastrointestinal cancers. The 100000 genomes project, ${ }^{3}$ a UK-wide project initiated by the Department of Health through Genomics England, represents a transformational programme to shift from a 'one-size-fits-all approach to healthcare towards a future of precision medicine'. ${ }^{4}$ This project has been made possible by ongoing dramatic technological advances, with the current ability to sequence an entire patient's exome (coding component of the genome) in less than a day, at a cost of well under $£ 500$ and falling. ${ }^{5}$ One of the main challenges for National Health Service (NHS) England as it establishes its new NHS Genomic Medicine 


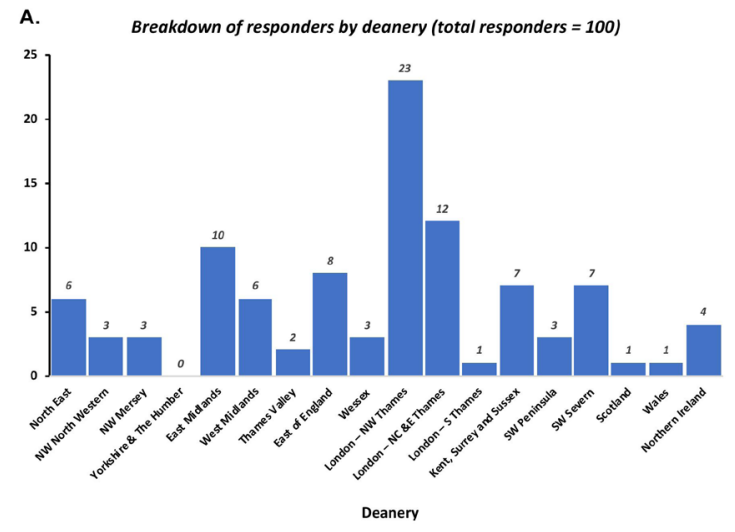

B.
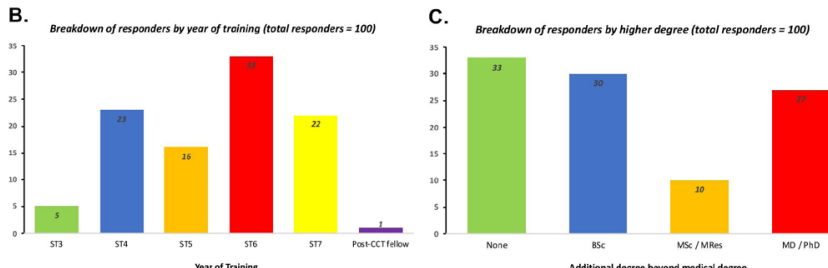

Figure 1 A breakdown of survey responders by deanery (A-top), year of training (B-bottom left) and additional degree ( $\mathrm{C}$-bottom right). ST, senior trainees; $\mathrm{CCT}$, Completion of Consultant Training.

services in the UK from October 2018 will be to shift much of the genomic testing away from clinical geneticists and towards an expanding group of front-line clinicians, and a need to establish the infrastructure necessary to integrate advanced genomics into mainstream NHS practice.

While upcoming cohorts of gastroenterology specialty trainees will benefit from the translational impact of genomic medicine, it is likely that they will, as future consultants, be expected to be at the forefront of this new paradigm of personalised medicine, by directly undertaking the necessary genomic investigations and subsequent interventions. However, current UK gastroenterology trainee exposure to genomic medicine is limited to optional 'out-of-programme' research opportunities and postgraduate educational courses, with only a basic understanding of clinical genetics required by the current Joint Royal College of Physicians training Board (JRCPTB) gastroenterology training curriculum. ${ }^{6}$ The higher training curricula of other specialties (eg, cardi$\operatorname{ology}^{7}$ and oncology ${ }^{8}$ ) have recently been revised with the addition of modular training in genomics. We, therefore, aim to capture the current state of genomics training in gastroenterology to review current understanding, clinical experience and long-term training needs of UK trainees, and to assess their preparedness for the future consultant practice.

\section{METHODS}

\section{Survey design and dissemination}

In November and December 2017, we conducted a web-based nationwide survey (using the SurveyMonkey ${ }^{9}$ platform) of all UK Gastroenterology specialty trainees, supported by the British Society of Gastroenterology (BSG) national training committee at the Royal College of Physicians. As this survey of NHS staff was conducted through the BSG national training committee, and does not require the divulging of sensitive or patient-identifiable data, UK Research Ethics Committee and NHS Health Research Authority regulatory permission were not required. An overview of the survey questions and formats is shown in the online supplementary section. The survey consisted of 12 questions, and used a combination of question formats, including multiple choice questions (5), multichoice checkboxes (1), rating scales (4) and free-text entries (2). There was no patient and public involvement required for this survey.

Links to the survey were forwarded to all deanery trainee representatives, who then disseminated this survey to all trainees via email. Survey respondents were asked to provide their name, so as to confirm the uniqueness of each survey response. Statistical analysis was conducted on SPSS, using Fisher's exact test to assess the significance of differences in categorical survey responses.

\section{Patient and public involvement}

We did not involve patients or the public in our work.

\section{RESULTS}

\section{Breakdown of responses}

One hundred trainees (representing 14\% of all 713 UK gastroenterology higher specialty trainees ${ }^{10}$ across 17 of 18 deaneries responded to this survey, representing a full range of gastroenterology registrar training levels. A breakdown of survey responders by location, grade and additional degree beyond their medical qualification is shown in figure 1 .

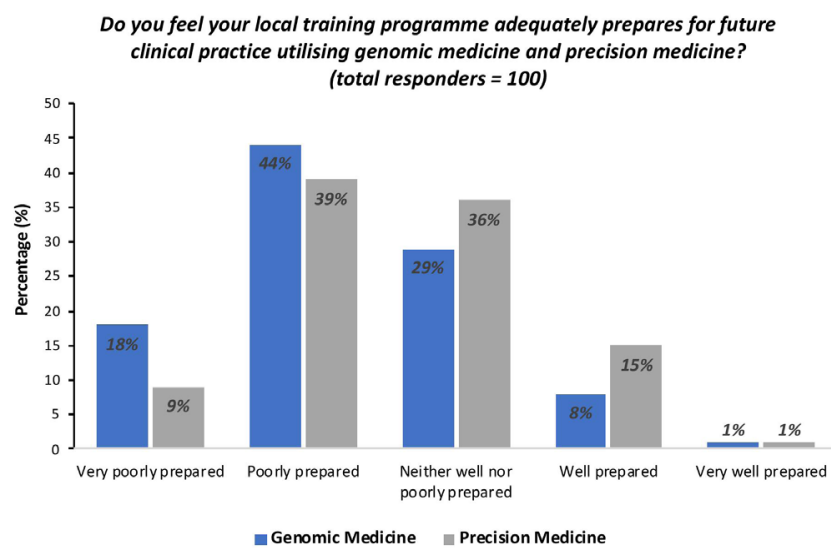

Figure 2 A breakdown of trainee survey responses according to their self-perceived preparedness for future practice using genomic medicine and precision medicine. 


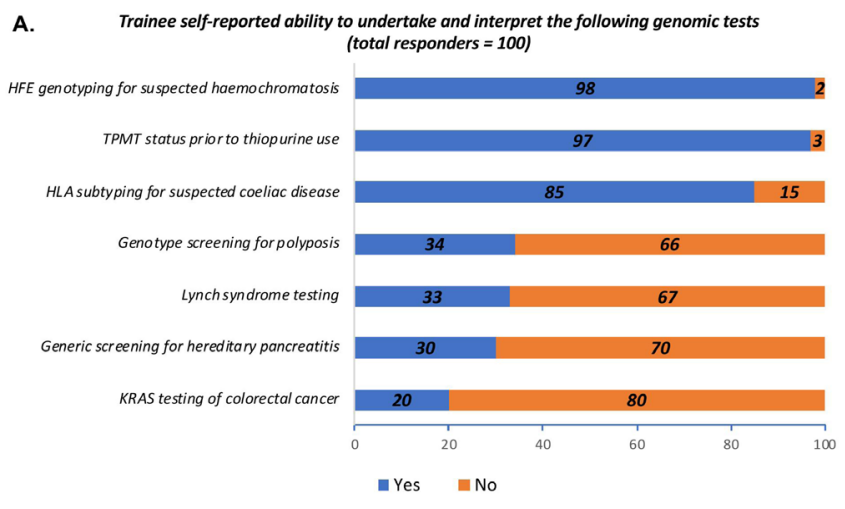

B.

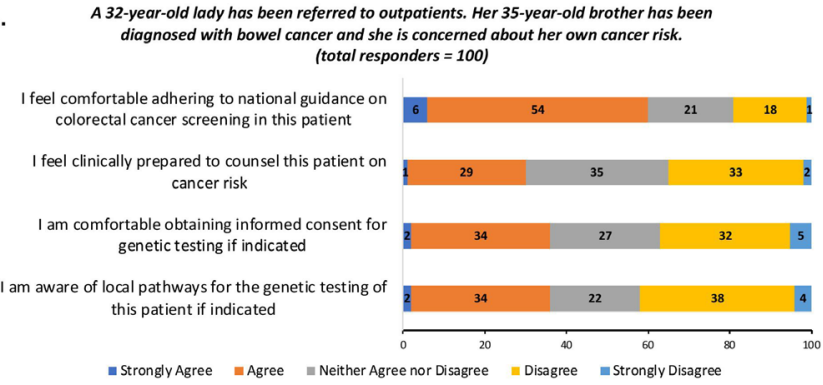

Figure 3 Self-reported competency in genetic testing relevant to gastrointestinal conditions. (A) Breakdown of survey responses relating to currently available genomic screening tests in gastroenterology. (B) Breakdown of survey responses for a case scenario relating to patients with a family history of colorectal cancer. TPMT, Thiopurine S-methyltransferase; HLA, Human leukocyte antigen.

\section{Survey responses relating to trainee perception of} preparedness and experience of genomic and precision medicine

Less than one-quarter (24\%) of survey respondents felt that they understood what mainstreaming of genomic practice entails for future clinical practice. While senior trainees (ST6 or ST7) are more likely than junior trainees (ST3-ST5 years) to understand what genomic mainstreaming entails $(27.8 \%$ vs $14.3 \%)$, this difference did not attain statistical significance $(p=0.19)$. Similar findings were noted for trainees with a higher postgraduate degree (Masters or $\mathrm{PhD}$ ) compared with those with a BSc or no additional degree $(33.3 \%$ vs $19.0 \%, \mathrm{p}=0.15)$. Moreover, only $9 \%$ and $16 \%$ of survey respondents believe that their local training programme adequately prepares them to use genomic medicine and personalised medicine, respectively (figure 2). Reflected in this, only $6 \%$ of respondents have recruited patients into the 100000 genomes project.

Survey responses relating to self-perception of enablement to conduct genetic testing relevant to gastrointestinal conditions As part of their survey, gastroenterology trainees were asked about their self-perceived enablement in undertaking and interpreting currently available tests (figure 3A). While respondents felt able to undertake and interpret HFE genotyping for haemochromatosis, TPMT status prior to thiopurine use and HLA subtyping for possible cases of coeliac disease $(98 \%, 97 \%$ and $85 \%$, respectively), only a minority of respondents felt enabled to undertake and interpret KRAS status testing of colorectal cancer, genetic screening for hereditary pancreatitis, Lynch syndrome testing and genetic screening for polyposis $(20 \%, 30 \%$, $33 \%$ and $34 \%$, respectively).

Trainees were then provided with a scenario commonly encountered in general gastroenterology clinics relating to the clinical management of a patient with a family history of colorectal cancer: a 32-year-old woman has been referred to clinic following the recent diagnosis of her 35-year-old brother with bowel cancer, as she is concerned about her own cancer risk. Although the majority of respondents felt comfortable adhering to existing national guidance on cancer screening in such a patient (with $60 \%$ agreeing or strongly agreeing), less than $40 \%$ felt clinically prepared to counsel this patient on her cancer risk, obtain informed consent for genetic testing if indicated, or were aware of local referral pathways for genetic services (figure 3B).

\section{Trainee responses regarding challenges relating to the} mainstreaming of genomic medicine, with supported future interventions

Gastroenterology trainees were subsequently asked about their views regarding recognised challenges related to the mainstreaming of genomic medicine (figure $4 \mathrm{~A}$ ). While an overwhelming majority of respondents agree that more education is needed before genomic testing can be mainstreamed (with $95 \%$ agreeing or strongly agreeing), and a majority of these trainees recognising that genetically determined disease are sufficiently common to justify mainstreaming of genomic testing in all secondary care centres, $53 \%$ of respondents believe that there is not enough clinical guidance at present to guide interventions based on the results of genetic testing. Trainees held mixed opinions regarding the risk of overuse/misuse of test results by clinicians, misinterpretation of results by patients, the cost-effectiveness of genomic testing and the adequacy of legal protections against discrimination for those individuals with genetic susceptibilities to disease. A substantial proportion of respondents expressed no firm opinion.

When surveyed about potential changes that would help trainees to use genomic medicine in their future practice, a majority supported the creation of dedicated training days focused on genomics by local deaneries, with updates to both the gastroenterology JRCPTB curriculum and specialty certificate examination and specific training in the mainstreaming of genomic tests (figure 4B). Although views on novel opportunities to undertake subspecialty training in were mixed, over $90 \%$ of trainees believed that there is a need for better defined pathways for referral to local genomic services. 
A.

Trainee support for selected interventions that promote genomic mainstreaming (total responders $=100$ )

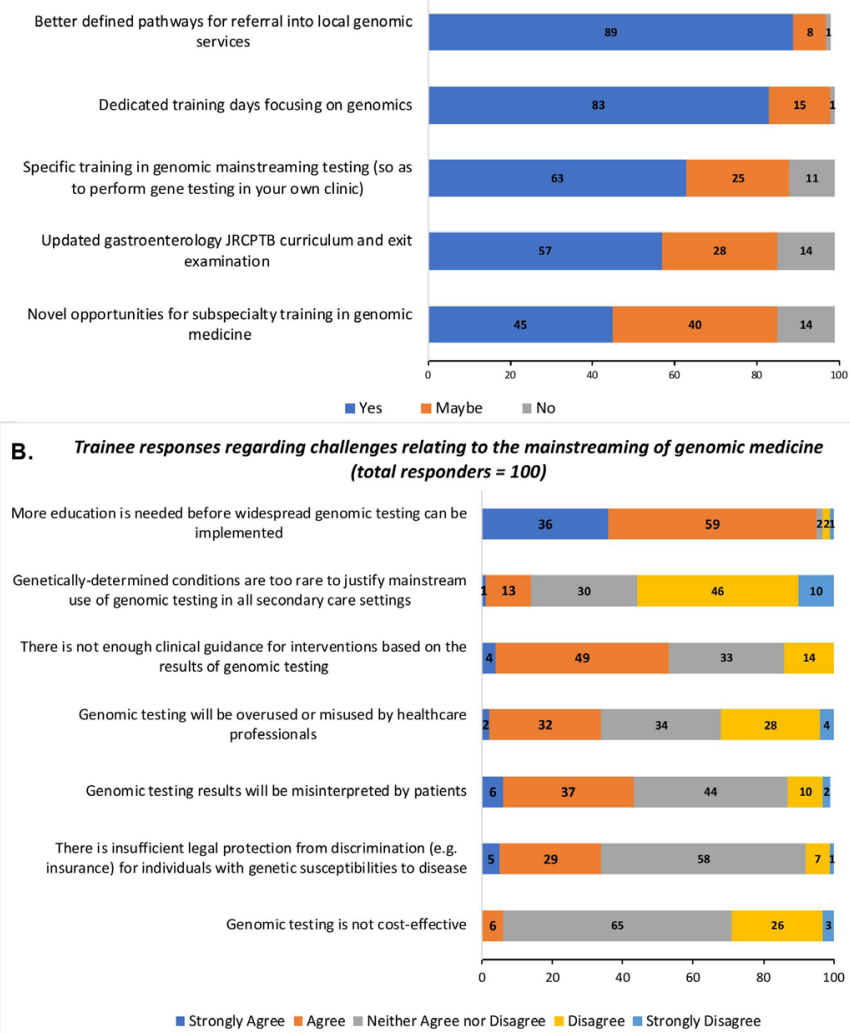

Figure 4 Trainee responses regarding challenges relating to the mainstreaming of genomic medicine, with supported future interventions. (A) Trainee support for selected interventions that promote genomic mainstreaming. (B) A breakdown of trainee responses regarding selected challenges posed by genomic mainstreaming. JRCPTB, Joint Royal College of Physicians training Board.

\section{DISCUSSION}

The mainstreaming of genomics involves the integration of newly developed genomic tests into a mainstream clinical approach, to be performed directly by front-line gastroenterologists rather than by clinical geneticists at specialist centres. Genomic mainstreaming has received political and financial support from the NHS, ${ }^{11}$ and has the potential to change the way future clinicians approach a whole host of gastroenterological conditions in terms of risk assessment, patient counselling and clinical intervention. Our survey demonstrates that the majority of survey respondents feel ill equipped to practise genomic and personalised medicine as consultants. Trainee involvement in current NHS efforts to mainstream genomic medicine remains limited at present with only a small minority of respondents involved in patient recruitment for the 10 000 genomes project. While this finding is unsurprising given the relatively circumscribed scope of the project at the time of the survey, it also reflects how genomic medicine in the NHS remains in its infancy. These findings pose a significant challenge to our specialty at a time of rapid ongoing changes to clinical guidelines and local service pathways necessary for successful mainstreaming of genomic practice.

This study is notable in that it presents findings from the largest survey of NHS staff addressing their views and experiences of genomic mainstreaming and precision medicine. Nevertheless, it faces several limitations. First and most notably is a trainee response rate of under $15 \%$. Due to the nature of an online anonymous survey, we have no information on non-responders to add context to the conclusions. The method of survey dissemination, via the BSG, means that the survey invitation would have been received by the overwhelming majority of UK gastroenterology trainees. While BSG membership is not mandatory, it is exceptionally unusual for a UK gastroenterology trainee to choose not to enrol into the specialty's professional society. A review of published literature involving surveys of BSG members unfortunately demonstrates that a low response rate is the norm and not the exception (as an example see reference 12). The reasons are unclear, but we speculate that this reflects apathy towards completing online surveys. We do not believe that trainees who responded are any more or less likely to be concerned about their lack of knowledge compared with the total trainee population. With over one-third of survey respondents holding a higher postgraduate degree (28\% held a $\mathrm{PhD}$ and $12 \%$ held an MSc), one would speculate that this cohort would be much more familiar with the mainstreaming of genomics. For the clear majority of responders, who were STs and/ or holders of a higher degree, to express concern about their knowledge base, represents an important finding in its own right. This declared lack of preparedness by survey respondents to practise genomic medicine in their future careers, and their demand for changes in service design, training and clinical guidelines, would go against participation bias in favour of trainees with existing research and/ or clinical experience in genomic medicine. Finally, the survey cohort is sufficiently large, with clear geographical, contextual and seniority variation among respondents so as to make conclusions generalisable.

Trainee responses on their ability to conduct currently available genomic tests encapsulate the nature of the challenge generated by the historical centralisation of clinical genetics testing and counselling services within the NHS. For example, trainee familiarity with TPMT status assessment reflects its routine use by gastroenterologists in patients being considered for thiopurine therapy because of conditions such as IBD and autoimmune hepatitis. This contrasts with the self-reported inability by the majority of survey respondents to conduct testing for Lynch syndrome, a condition with a UK prevalence (at 1 in 450) that is comparable to that of IBD, and where the UK National Institute of Clinical Excellence recommends Lynch syndrome screening of every patient with colorectal cancer. ${ }^{13}$ As part of the drive by the NHS to mainstream genomic medicine, there is an expectation that these tests will no longer be conducted by clinical geneticists in the future, but rather by front-line clinicians such as gastroenterologists. 
We propose that the UK gastroenterology specialty curriculum requires specific revision to prepare trainees for genomics in their future clinical practice. Similar efforts have been undertaken recently by other medical specialties, most notably by the cardiology section of the JRCPTB in the creation of a dedicated advanced subspecialty module in inherited cardiovascular conditions aimed at final year trainees and post-CCT (Completion of Consultant Training) fellows. ${ }^{7}$ Our proposed curriculum modifications include, but are not limited to, the addition of the following competencies:

- An understanding of the clinical utility and limitations of genetic diagnoses, as well as the concepts of heredity, clinical penetrance, genotype-phenotype variation and the principles of genetic screening.

- An understanding of the basic principles underlying next-generation sequencing techniques.

- An understanding of the genetics of normal, premalignant and cancerous cells.

- Practical appraisal of trainees on how and when to use a genomic test, how to interpret test results, and of trainee competence in communicating test results as well as in clinical decision-making based on test results. Guidance on the establishment of formal standards in these domains has been generated by organisations such as the Public Health Genomics Foundation. ${ }^{11}$ Trainee appraisals can be conducted using existing JRCPTB workplace-based assessment tools. ${ }^{14}$

We also recommend the implementing of programmes / activities indicated by trainees in the survey, such as the creation of better-defined pathways for referral to local genomic services, and updates of the newly formed European Specialty Examination in Gastroenterology and Hepatology UK gastroenterology specialty certificate examination to reflect the likely competency requirements for future front-line clinicians. In addition to the provision of dedicated training days on genomic medicine in every deanery, other creative education initiatives, combining web-based resources with immersive learning techniques and interdisciplinary training by NHS clinical genetics service providers, should be considered. ${ }^{15}$ Finally, while gastroenterology trainees are expected to be aware of all currently available tests listed in figure $3 \mathrm{~A}$ as part of their specialty accreditation, an expanding plethora of disease-specific precision tests may require that future clinical implementation be limited to subspecialists within gastroenterology. Expectations on trainee, general consultant and subspecialty consultants will need to be defined. For genomic mainstreaming to be successfully implemented in the specialty, it is, therefore, incumbent on organisations such as the BSG to issue, where relevant, regularly updated position statements that provide guidance on NHS service expectations in genomic/precision testing, alongside clear guidelines for practising clinicians to follow when applying the results of these tests.
Author affiliations

${ }^{1}$ Centre for Tumour Biology, Barts Cancer Institute, London, UK

${ }^{2}$ Department of Gastroenterology, St. Mark's Hospital, Harrow, UK

${ }^{3}$ Department of Gastroenterology, University College Hospitals NHS Foundation

Trust, London, UK

${ }^{4} \mathrm{PHG}$ Foundation, University of Cambridge, Cambridge, UK

${ }^{5}$ Family Cancer Clinic, St. Mark's Hospital, Harrow, UK

${ }^{6}$ Genomic Medicine, Imperial College, London, United Kingdom

Acknowledgements We would like to thank the 2017-2018 British Society of Gastroenterology national trainees committee representatives for their assistance in distributing the survey to trainees in their respective deaneries.

Contributors $I A B$ and KJM were responsible for survey design and dissemination. $I A B$ and GMS-R were responsible for analysis of survey results and drafting of the manuscript. HB and KJM provided senior support and critical appraisal during survey result analysis and manuscript drafting.

Funding The authors have not declared a specific grant for this research from any funding agency in the public, commercial or not-for-profit sectors.

Competing interests None declared.

Patient consent for publication Not required.

Provenance and peer review Not commissioned; externally peer reviewed.

Data availability statement Data are available on reasonable request.

Open access This is an open access article distributed in accordance with the Creative Commons Attribution Non Commercial (CC BY-NC 4.0) license, which permits others to distribute, remix, adapt, build upon this work non-commercially, and license their derivative works on different terms, provided the original work is properly cited, appropriate credit is given, any changes made indicated, and the use is non-commercial. See: http://creativecommons.org/licenses/by-nc/4.0/.

\section{ORCID iD}

Ibrahim Al Bakir http://orcid.org/0000-0001-8775-3459

\section{REFERENCES}

1 van Dijk EL, Auger H, Jaszczyszyn $\mathrm{Y}$, et al. Ten years of nextgeneration sequencing technology. Trends Genet 2014;30:418-26.

2 Stephens MC, Boardman LA, Lazaridis KN. Individualized medicine in gastroenterology and hepatology. Mayo Clin Proc 2017;92:810-25.

3 Turnbull C, Scott RH, Thomas E, et al. The 100000 Genomes Project: bringing whole genome sequencing to the NHS. BMJ 2018;361:k1687.

4 England NHS. Improving outcomes through personalised medicine, 2016.

5 Schwarze K, Buchanan J, Taylor JC, et al. Are whole-exome and whole-genome sequencing approaches cost-effective? A systematic review of the literature. Genet Med 2018;20:1122-30.

6 Joint Royal Colleges of Physicians Training Board. Specialty training curriculum for gastroenterology, 2010.

7 Joint Royal Colleges of Physicians Training Board. Specialty training curriculum for cardiology, 2010.

8 Royal College of Radiology. Specialty training curriculum for clinical oncology, 2016.

9 SurveyMonkey Inc. San Mateo. California, USA.

10 Federation of the Royal Colleges of Physicians of the UK. Census (UK consultants and higher specialty trainees), 2016-2017.

11 Burton H, Hall A, Kroese M, et al. Genomics in mainstream clinical pathways, 2017. Available: http://www.phgfoundation.org/ documents/PHGF-Genomics-in-mainstream-clinical-pathways.pdf [Accessed 1 May 2018].

12 Monahan KJ, Clark SK, British Society of Gastroenterology (BSG) Cancer Group. A national survey of hereditary colorectal cancer services in the UK. Frontline Gastroenterol 2014:5:130-4.

13 National Institute for Health and Care Excellence (NICE). Molecular testing strategies for Lynch syndrome in people with colorectal cancer, 2017.

14 Joint Royal College of Physicians Training Board - Workplace Based Assessment. Available: https://www.jrcptb.org.uk/assessment/ workplace-based-assessment [Accessed 23 Aug 2018].

15 Rubanovich CK, Cheung C, Mandel J, et al. Physician preparedness for big genomic data: a review of genomic medicine education initiatives in the United States. Hum Mol Genet 2018;27:R250-8. 